\title{
Validation of the Children's Social Understanding Scale for Assessing Korean Preschoolers' Theory of Mind
}

\author{
Sun-Young Yoon ${ }^{1}$, Nana Shin ${ }^{2}$ \\ Ph. D., Department of Child Development \& Intervention, Ewha Womans University, Seoul, Korea ${ }^{1}$ \\ Associate Professor, Department of Child Development \& Intervention, Ewha Womans University, Seoul, Korea ${ }^{2}$ \\ 한국 유아의 마음이론 측정을 위한 사회적 이해 척도의 타당화 연구 \\ 윤선영 ${ }^{1}$, 신나나 ${ }^{2}$ \\ 이화여자대학교 아동학과 박사 ${ }^{1}$, 이화여자대학교 아동학과 부교수 ${ }^{2}$
}

Objectives: The main purpose of this study was to validate the Children's Social Understanding Scale (CSUS), which was developed and validated by Tahiroglu et al. (2014).

Methods: A total of 530 preschoolers and their mothers participated in a series of studies designed to validate the CSUS. The mothers responded to questions related to the preschoolers' Theory of Mind (ToM), executive function, and their parenting behaviors. The preschoolers were given a series of ToM tasks and a verbal ability test. The psychometric properties of the CSUS were assessed in three studies.

Results: Study 1 examined content validity of the CSUS through expert evaluation, construct validity through confirmatory factor analysis, and reliability through internal consistency and test-retest reliability coefficients. Study 2 tested convergent validity by examining the relationships between the CSUS and the ToM task scores. In Study 3, a confirmatory factor analysis was conducted to evaluate cross-validation using different samples of preschoolers. In addition, concurrent validity was confirmed by the association among the CSUS, executive function, and parenting behaviors.

Conclusion: The findings of this study indicate that the CSUS is a reliable and valid measure of preschoolers' theory of mind. The CSUS can be used as a tool for estimating individual differences in preschoolers' ToM, as well as correlations with other aspects of development.

Keywords: Children's Social Understanding Scale, theory of mind, preschooler, psychometric properties

\section{Introduction}

인간은 사회적 존재로, 타인과의 원활한 사회적 상호작용을 위해서는 타인의 마음과 행동을 이해하는 능력이 필수적이다 (Flavell, Miller, \& Miller, 1993). 즉, 타인의 마음상태뿐 아니라 자 신의 행동이 타인의 마음과 행동에 어떠한 영향을 미치는지, 그

Corresponding Author: Nana Shin, Associate Professor, Department of Child Development \& Intervention, Ewha Womans University, Human Ecology Building 402-1, 52 Ewhayeodae-gil, Seodaemun-gu, Seoul, Korea E-mail: nanashin@ewha.ac.kr
리고 마음상태와 겉으로 드러나는 행동은 다를 수 있음을 이 해해야 한다. 이러한 능력을 지칭하는 것이 마음이론(theory of mind)으로, 유아기 동안 급격하게 발달하는 것으로 알려져 왔 다(Gopnik \& Slaughter, 1991; Wellman, 1992). 이 시기 마음이론 을 형성하는 것은 유아가 또래집단에서 긍정적으로 적응하는 데 요구되는 필수적인 능력 중 하나로(Hughes \& Leekam, 2004),

(C)The Korean Association of Child Studies

This is an Open Access article distributed under the terms of the Creative Commons Attribution Non-Commercial License (http:// creativecommons.org/licenses/by-nc/4.0) which permits unrestricted noncommercial use, distribution, and reproduction in any medium, provided the original work is properly cited. 
관련 연구들은 마음이론이 높은 유아가 또래 내 인기가 높고 (Slaughter, Imuta, Peterson, \& Henry, 2015), 사회적으로 유능하며 (Imuta, Henry, Slaughter, Selcuk, \& Ruffman, 2016; Walker, 2005), 학업성취가 높은 것으로 보고하고 있다(Blair \& Razza, 2007).

현재까지 수행된 마음이론 연구들은 대부분 마음이론 과제 를 제시한 후 이에 대한 유아의 수행을 측정하는 방식으로 진 행되었으며(Carlson \& Moses, 2001; Perner, Lang, \& Kloo, 2002; Ruffman, Perner, \& Parkin, 1999; Wellman, Cross, \& Watson, 2001), 이러한 연구들을 통해 영유아기 마음이론의 출현 시 기나 발달 양상에 대한 현재의 지식이 형성되었다. 마음이론 연구의 초기 단계인 1980-90년대 수행된 연구들은 주로 틀린 믿음에 초점을 둔 과제를 사용하여 마음이론을 측정하였다 (Ruffman et al., 1999; Wimmer \& Perner, 1983). 하지만 단일 과 제를 사용하여 마음이론을 측정할 경우 다양한 마음상태나 시 간의 흐름에 따른 마음이론의 안정성에 대한 정보를 제공하 기에는 한계가 있음이 제안되었다(Blijd-Hoogewys, van Geert, Serra, \& Minderaa, 2008; Tahiroglu et al., 2014). 이러한 제한점 을 극복하기 위해 연구자들은 마음상태를 측정하는 다양한 과 제들을 함께 사용함으로써 측정의 정확성과 타당성을 높이고 자 하였다(Hughes et al., 2000; Wellman \& Liu, 2004).

마음이론 과제는 실험실 상황에서 유아의 수행을 평가함 으로써 유아의 마음이론을 직접적으로 평가할 수 있다는 장 점이 있으며, 다양한 과제의 합계를 사용할 경우 신뢰성 또 한 높은 것으로 보고되었다(Hughes et al., 2000). 그러나 과제 를 통한 측정에도 제한점은 존재하는데, 실험실에서의 측정 은 유아의 일상적인 행동, 의사소통 및 사회적 상호작용에서 나타나는 마음이론을 충분히 포함하지 못할 수 있으며(Raver \& Leadbeater, 1993), 유아의 인지나 언어능력(Happé, 1995), 수줍음과 같은 기질적인 특성(Tager-Flusberg, 1999)에도 영향 을 받을 수 있다. 이에 일상생활에서 보이는 마음이론을 측정 하는 척도를 개발하여 마음이론을 보다 통합적으로 측정하 고자 하는 시도가 나타나기 시작하였다(Hutchins, Prelock, \& Bonazinga, 2012; Tahiroglu et al., 2014). 척도를 통한 측정은 자 료수집에 소요되는 시간과 비용에서의 경제성으로 인하여 대 규모의 집단을 대상으로 사용하기에 보다 용이하다. 또한 자 녀에 대한 전문가적 지식을 가지고 있으며(Prelock, 2006), 다 양한 상황에서 자녀를 관찰할 수 있는 부모가 보고자가 되어 자녀의 일상적인 행동이나 상태를 평가할 경우 생태학적 타당 도가 높다는 장점이 있다(Newton, Reddy, \& Bull, 2000). 물론 부모 보고의 경우 부모의 주관적인 견해를 반영하거나 사회적 바람직성(social desirability)이 작용하여 자녀의 행동을 객관적
으로 묘사하지 못할 가능성도 제기되고 있다(Miller, 1986). 하 지만 부모 보고는 전문가(Gradel, Thompson, \& Sheehan, 1981) 나 교사 보고(Renk \& Phares, 2004)와 유의한 상관을 보이는 것 으로 나타나, 부모가 유아기 자녀의 행동 특성이나 성향 등에 대한 적절한 보고자로 활용될 수 있음을 제안하고 있다.

Tahiroglu 등(2014)은 부모보고를 통해 만 3-6세의 마음이론 을 측정하는 사회적 이해 척도(Children's Social Understanding Scale [CSUS])를 개발하였으며, 문항 간 높은 내적합치도와 검사-재검사 신뢰도를 통해 신뢰도를 확인하였다. 또한 요인 분석을 통해 척도의 구인타당도를 입증하고, 과제를 통해 측 정된 마음이론과의 적절한 상관관계를 밝혔으며, 마음이론 과 밀접하게 관련된 인지능력과의 유의한 상관관계를 확인 함으로써 척도의 타당성을 입증하였다. 이후 CSUS는 폴란 드(Smogorzewska, Szumski, \& Grygiel, 2019), 터키(Besiroglu, Selcuk, \& Tahiroglu, 2017), 중국(Gluck, Paik, Duh, Moses, \& Nelson, 2017) 등에서 타당성이 검증되어 다양한 문화권에서 사용가능한 척도임이 밝혀졌다.

본 연구는 CSUS가 국내 유아의 마음이론을 측정하는 데 타 당하게 사용될 수 있을지 확인하기 위하여 CSUS의 신뢰도와 타당도를 검증하는 것을 목적으로 하였다. CSUS의 심리측정 적 특성(psychometric properties)을 확인하기 위하여 신뢰도의 경 우, 각 문항에 대해 일관적으로 응답하는지 측정하는 내적합치 도를 산출하였고, 동일한 측정을 반복 실시하였을 때 유사하게 응답하는지 살펴보는 검사-재검사 신뢰도를 산출하였다. 타당 도의 경우, 척도 개발 시 주로 제안되는 세 가지 타당도(DeVellis, 2016)인 내용타당도, 구인타당도, 공인타당도를 검증하였으며, 교차타당도를 통해 일반화 가능성 또한 확인하고자 하였다. 먼 저 내용타당도는 CSUS의 적절성과 명확성에 대한 전문가들의 평가를 통해 검증하였으며, 구인타당도는 척도의 이론적 구조 를 검증한 확인적 요인분석과 마음이론 과제(Carlson \& Moses, 2001; Wellman \& Liu, 2004)와의 상관을 분석한 수렴타당도를 통해 검증하였다. 또한 준거관련 타당도의 일종인 공인타당도 는 선행연구들에서 마음이론과 관련이 높은 것으로 밝혀진 언 어능력(Astington \& Baird, 2005; DeVilliers, 2007)과 실행기능 (Blair \& Razza, 2007; Carlson, Moses, \& Breton, 2002), 그리고 어 머니의 양육행동(Astington \& Jenkins, 1999; Jang \& Shin, 2018) 과의 상관을 검증함으로써 확인하였다. 마지막으로, 확인적 요 인분석을 통해 도출된 모형이 연구대상이 다른 집단에서도 동 일하게 나타나는지 살펴보는 교차타당도를 검증하였다.

준거 변인으로 설정된 언어능력, 실행기능 및 어머니의 양 육행동과 마음이론 간의 관련성을 살펴보면, 먼저 유아기 언 
어능력은 마음이론과 밀접한 관계를 보이는데(Astington \& Baird, 2005), 언어능력은 내적인 바람을 외적으로 표현하는 상호작용의 중요한 매개체가 된다는 점에서 마음이론의 발달 과 관련이 있다(DeVilliers, 2007). 또한 상호작용 시 자신 및 상 대방의 마음상태는 언어를 통해 공유되므로 유아가 나누는 대 화는 타인과의 관계 및 사회적 세계를 이해하게 한다(Bartsch \& Wellman, 1995). DeVilliers (2007)는 마음이론의 대표적 과 제인 틀린믿음에 대한 이해는 어떤 문장이 다른 문장 안에 내 포되는 보문 구조(sentential complement)를 이해해야 가능하기 때문에 유아의 마음이론과 언어능력은 밀접하게 관련된다고 주장하였다. 즉, '나는 비가 온다고 생각해요.'와 같이 마음상 태를 나타내는 '생각하다', '믿다', '기억하다' 등의 인지 동사를 내포한 보문구조는 틀린믿음에 대한 이해를 언어적으로 표현 하므로, 보문구조의 습득은 틀린믿음의 발달에 영향을 미친다 고 하였다. 이외에도 Milligan, Astington과 Dack (2007)은 만 7 세 이하의 유아를 대상으로 틀린믿음에 대한 이해와 언어능력 간의 관계를 살펴본 104 편의 연구를 메타분석하여 마음이론 과 언어능력 간의 유의한 관계를 확인하였다.

다음으로, 실행기능은 사고, 정서, 행동을 관장하는 고차원 적인 인지적 조절능력을 의미하는 것으로, 억제, 주의전환, 작 업기억, 계획 및 조직화, 감정조절 등의 하위영역을 포함한다 (Gioia, Espy, \& Isquith, 2003). 마음이론과 실행기능은 모두 유 아기에 급격하게 발달하며(Wellman et al., 2001), 전두엽의 발 달과 관련된다는(Sabbagh \& Taylor, 2000) 공통점을 가지고 있 다(Carlson \& Moses, 2001). 선행연구들은 과제수행을 통해 측 정한 마음이론과 실행기능 간의 관련성을 밝히고 있으며, 실 행기능의 하위요인 중에서도 억제 및 작업기억이 마음이론 과 가장 밀접하게 관련되는 것으로 보고하였다(Carlson et al., 2002; Perner et al., 2002). CSUS가 비교적 최근에 개발된 척도 이기 때문에 그 수는 적지만 CSUS로 측정한 유아의 마음이론 과 실행기능 간의 관련성을 밝힌 연구들도 점차 보고되고 있 다(Jang \& Shin, 2018; Nelson, 2017).

마지막으로, 어머니의 양육행동은 마음이론의 발달에 영 향을 미치는 환경적 요인으로, 긍정적인 양육행동은 자녀의 높은 수준의 마음이론과 관련이 있는 것으로 나타났다. 어머 니가 유아에게 논리적인 설명을 해주고 긍정적인 상호작용을 많이 할수록 유아는 타인에 대한 이해수준이 높았으며(Bae \& Choi, 2002), 자신의 의견을 표현하게 하거나 마음상태에 대 한 대화를 많이 나눌 경우 유아가 높은 수준의 마음이론을 보 였다(Dunn \& Brown, 1993; O’Reilly \& Peterson, 2014). 마음 이론과 양육행동 간의 관계를 살펴본 연구들은 주로 마음이
론 과제를 사용하여 관련성을 밝혔지만, CSUS를 통해 측정 한 마음이론과 양육행동 간의 관계를 살펴본 연구들도 점차 나타나고 있다. 이러한 연구들에서는 부모가 온정 및 논리적 설명 등의 민주적 양육행동을 더 보일수록 유아가 높은 수준 의 마음이론을 보이는 것으로 보고하였다(Jang \& Shin, 2018; Smogorzewska et al., 2019).

유아기 마음이론의 발달은 여러 문화권에서 유사하게 나타 나지만, 마음이론과 관련 변인들 간의 관계에서는 다른 양상 을 보이기도 하여(Vinden, 2001) 비교문화연구의 필요성이 제 안되고 있다(Sabbagh, Xu, Carlson, Moses, \& Lee, 2006; Vinden, 2001). 예를 들어, 마음이론과 양육행동 간의 관계는 문화에 따 라 다소 차이를 보였는데, 한국계 미국인 어머니들의 경우 권 위주의적 양육과 마음이론 간 관계가 유의하지 않았지만, 영국 계 미국인 어머니들의 경우 권위주의적 양육을 더 보일수록 유 아가 낮은 수준의 마음이론을 보여 사회문화적 맥락에 따라 마 음이론과 관련 변인들 간의 관계가 다르게 나타날 수 있음이 보고되었다(Vinden, 2001). 따라서 국내에서 타당화된 CSUS는 마음이론과 관련된 여러 변인들 간의 관계에서 발생할 수 있는 문화적 차이를 연구하는 비교문화연구의 도구가 될 수 있을 것 이며, 마음이론 연구의 활성화에 기여할 수 있을 것이다.

종합하면, 본 연구는 만 3-6세 유아를 대상으로 국외에서 개 발된 마음이론을 측정하는 척도인 CSUS의 심리측정적 특성을 확인하는 것을 주목적으로 하였다. 이를 위해 세 개의 연구를 구성하였는데, 각 연구는 연구대상, 측정도구, 그리고 검증하 고자 하는 타당도에서 차이를 보인다. 각각을 살펴보면, 연구 1 에서는 내용타당도 및 구인타당도와 함께 신뢰도를 검증하여 이후 연구에서 사용될 척도를 확정하였고, 연구 2에서는 연구 1 에서 확정된 CSUS와 실험실 상황에서 측정한 마음이론과 언 어능력 간의 상관을 살펴봄으로써 수렴타당도와 공인타당도 를 검증하였다. 마지막으로 연구 3에서는 새로운 집단을 대상 으로 CSUS의 교차타당도를 살펴보고, 실행기능과 어머니의 양육행동과의 상관을 통해 공인타당도를 검증하였다.

\section{[연구 1]}

\section{연구문제 1}

마음이론 척도의 타당도(내용타당도, 구인타당도)는 어떠한가?

\section{연구문제 2}

마음이론 척도의 신뢰도(내적합치도, 검사-재검사 신뢰도)는 어떠한가? 


\section{Methods}

\section{연구대상}

연구 1 의 연구대상은 원척도를 개발한 연구(Tahiroglu et al., 2014)와 같은 연령인 만 3-6세 유아 252명으로, 어머니가 유아 의 마음이론에 대해 응답하였다. 연구대상의 사회인구학적 특 성을 살펴보면, 성별의 경우 남아 130 명(51.6\%), 여아 122 명 (48.4\%)으로 비슷한 비율이었다. 평균 월령은 56.47 개월 $(S D=$ 12.79)로, 만 3세 72명(28.6\%), 만 4세 77명(30.6\%), 만 5세 52 명(20.6\%), 만 6세 51명(20.2\%)이었다. 자녀의 출생순위는 첫 째가 181 명 $(71.8 \%)$ 으로 가장 많았으며, 둘째가 62 명 $(24.6 \%)$ 이었다. 부모의 평균 연령은 어머니가 35.52 세 $(S D=4.69)$, 아버지가 37.53세 $(S D=5.12)$ 였으며, 어머니와 아버지 모두 35-39세가 103명(40.9\%)과 100명(39.7\%)으로 가장 많았다. 부모의 교육수준은 어머니와 아버지 모두 대졸이 각각 161 명 (63.9\%)과 168명(66.7\%)으로 가장 높은 비율을 나타냈다.

검사-재검사 신뢰도를 위하여 연구 1 에 참여한 어머니 중 30 명이 3 주 후 마음이론 척도에 재응답하였다. 이들의 사회인 구학적 특성을 살펴보면, 성별의 경우 남아 15 명 $(50.0 \%)$, 여아 15 명(50.0\%)으로 동일한 비율이었으며, 평균 월령은 54.53개 월 $(S D=11.67)$ 로, 만 3세 8명 $(26.7 \%)$, 만 4세 6명 $(20.0 \%)$, 만 5 세 8명(26.7\%), 만 6세 8명(26.7\%)이었다. 자녀의 출생순위는 첫째가 19명(63.3\%)으로 가장 많았으며, 둘째가 9명(30.0\%) 이었다. 부모의 평균 연령은 어머니는 36.17 세 $(S D=4.71)$, 아버지가 39.10세 $(S D=5.03)$ 였으며, 어머니와 아버지 모두 35-39세가 12명(40.9\%)과 12명(40.0\%)으로 가장 높은 비율을 나타냈다. 부모의 교육수준은 어머니와 아버지 모두 대졸이 각각 14 명(46.7\%)과 19 명(63.3\%)으로 가장 많았다.

\section{연구도구}

유아의 마음이론은 Tahiroglu 등(2014)이 개발한 사회적 이 해 척도(CSUS)를 사용하여 측정하였다. CSUS는 총 42문항 으로 믿음, 지식, 지각, 바람, 의도, 정서의 6 개의 하위요인으 로 구성되었다. 문항의 예로, 믿음(7문항)은 "자신과 다른 사 람의 믿음이 어떻게 다른지 이야기한다.", 지식(7문항)은 “자 신이 어떻게 그 사실을 알게 되었는지 말할 수 있다.”, 지각(7 문항)은 "겉으로 보이는 것과 실제의 차이에 대해 이야기한 다.”, 바람(7문항)은 “사람들마다 좋아하는 것이나 원하는 것 이 다르다는 것을 이야기한다.", 의도(7문항)는 “의도적인 행
동과 실수로 인한 행동이 다르다는 것을 이해한다.”, 정서(7문 항)는 "다른 사람의 감정을 이해하려고 노력한다." 등이 있다. 각 문항은 어머니 보고를 통한 4점 Likert식 척도로 응답되었 으며, 점수가 높을수록 마음상태에 대한 이해가 높은 것을 의 미한다. Tahiroglu 등(2014)이 제시한 전체 문항의 내적합치도 (Cronbach's $\alpha$ )는 연구집단에 따라 .90 .94이었으며, 본 연구의 척도의 신뢰도는 연구결과에 제시하였다.

\section{연구절차}

연구에 앞서 CSUS 개발의 공동연구자인 Louis J. Moses에게 이 메일을 통하여 CSUS의 사용 및 타당화에 대한 동의를 얻었다. 이후 CSUS의 번역 및 역번역 과정을 거쳤으며, 국문학자에게 감수를 받아 표현을 수정하였다. 그 후 아동학과 교수 3 인과 유아교육과 교수 1 인의 전문가 집단에게 문항들이 마음이론의 해당 영역들을 적절하면서도 명확히 나타내고 있는지 검증받 았다. 본조사 실시에 앞서 만 3-6세의 자녀를 둔 10명의 어머니 를 대상으로 예비조사를 실시하여 문항의 이해도와 응답에 소 요되는 시간을 점검하였다. 그 결과, 문항의 이해에 어려움은 없는 것으로 나타났으며, 전체 문항에 응답하는 데에 약 10 분 이 소요되었다. 연구 1 의 연구대상은 온라인 설문조사기관을 통해 2018년 9월 모집되었으며, 총 252명의 대상 중 30명에게 3 주 후 재검사를 실시하였다. 재검사를 통해 수집된 자료는 검 사-재검사 신뢰도를 측정하는 목적으로만 사용되었다.

\section{자료분석}

수집된 자료는 SPSS 21.0 (IBM Co., Armonk, NY)과 AMOS 21.0 (IBM Co., Armonk, NY)을 이용하여 분석하였다. 먼저 연구대상의 일반적인 특성과 평균 및 표준편차를 살펴보기 위해 기술통계분석을 실시하였다. 그리고 구인타당도를 검 증하기 위하여 확인적 요인분석을 실시하였으며, 이 때 모 형의 적합도를 평가하기 위해 표본의 크기에 영향을 받는 다는 제한점이 있는 $\chi^{2}$ (Kline, 2015)와 $\chi^{2} / d f$ 와 함께 TuckerLewis Index (TLI), Comparative Fit Index (CFI) 및 Root Mean Square of Approximation (RMSEA) 등의 적합도 지수를 살펴보 았다. 다음으로 척도의 신뢰도를 확인하기 위해 내적합치도 (Cronbach's $\alpha$ )를 산출하였고, 상관분석을 통해 검사-재검사 신뢰도를 확인하였다. 


\section{Results}

\section{내용타당도 검증과 예비조사}

CSUS의 내용타당도를 살펴보기 위해 번역 및 역번역 과정과 국문학자의 검토를 거친 CSUS에 대해 4 인의 전문가(아동학 과 교수 3 명, 유아교육과 교수 1 명)가 문항의 의미의 명확성, 내용의 적절성 등을 검토하였다. 전혀 명확하지 않음에서 매 우 명확함까지 1-5점으로 평가하였고, 명확하지 않을 경우 그 에 대한 의견을 서술하여 기재하였다. 의견이 제기된 문항들 은 전문가와 함께 검토하여 수정여부를 결정하였다. 이를 바 탕으로 총 42 문항 중 11 문항이 문장의 명확성을 높이기 위해 수정되었는데 예를 들면, "목소리나 얼굴 표정만으로 당신의 기분을 알아차리지 못한다.”가 “목소리나 얼굴 표정만으로는 엄마나 아빠의 기분을 알아차리지 못한다.”로 변경되었다. 이 후 실제 본 연구의 연구대상과 동일한 연령대의 유아기 자녀 를 둔 어머니 10 명을 대상으로 예비조사를 실시하였다. 유아 의 연령은 만 3 세 2 명, 만 4 세 4 명, 만 5 세 4 명이었으며, 성별은 남아 6명, 여아 4 명이었다. 그 결과, 문항을 이해하거나 의미 를 파악하는 데 어려움은 보고되지 않았다.

\section{구인타당도 검증}

구인타당도를 검증하기 위해 확인적 요인분석(confirmatory factor analysis)을 실시하였다. CSUS의 문항들이 이론적 구조 에 적합한지 파악하기 위하여 원척도 개발 연구(Tahiroglu et al., 2014)의 제안을 따라 단일요인 모형을 검증하였으며, 추 가적으로 6 개의 하위요인으로 구분된 6요인 모형을 설정하여 각각 모형의 적합도를 검증하였다. 분석 결과(Table 1), 단일요 인 모형의 적합도 지수는 $\chi^{2}(710)=929.56(p<.001), \chi^{2} / d f=$ $1.30, \mathrm{TLI}=.92, \mathrm{CFI}=.94, \mathrm{RMSEA}=.04(90 \% \mathrm{CI}[.03, .04])$ 로 나타나, 적절한 수준의 적합도 기준을 충족하였다. 6 요인 모 형의 경우 적합도는 $\chi^{2}(700)=1356.26(p<.001), \chi^{2} / d f=1.92$,
$\mathrm{TLI}=.77, \mathrm{CFI}=.81, \mathrm{RMSEA}=.06(90 \% \mathrm{CI}[.06, .07])$ 으로 나 타나 적합하지 않았다. 본 연구의 결과는 원척도에서 제안한 바와 같이 전체가 하나의 단일요인으로 구성된다는 것을 지지 하였으며, 따라서 이후의 분석에서는 척도를 단일요인으로 처 리하여 사용하였다.

\section{신뢰도 검증}

CSUS의 전체 문항의 내적일합치도는 .90으로, Tahiroglu 등 (2014)의 연구에서 보고된 전체 문항 간 신뢰도인 .90 .94와 유 사하였다. 검사-재검사 신뢰도를 확인하기 위해 연구 1 에 참여 한 252 명 중 30 명에게 3 주 후 동일한 척도로 재검사를 실시하 여 두 측정결과 간의 상관계수를 산출하였다. 그 결과, 전체 문 항의 검사-재검사 신뢰도는 .74로 나타나, Tahiroglu 등(2014) 이 척도 개발 시 밝힌 검사-재검사 신뢰도인 .88보다 다소 낮게 나타났다. 하지만, 구인타당도 조사의 초기 단계에서 .70 정도 의 신뢰도를 가진 도구를 사용하는 것이 효율적일 수 있으므로 (Nunnally \& Bernstein, 1994) 이는 양호한 수준이라 할 수 있다.

[연구 2]

\section{연구문제 1}

마음이론 척도의 수렴타당도와 공인타당도는 어떠한가?

\section{Methods}

\section{연구대상}

연구 2의 연구대상은 만 3-6세 유아 58명으로 유아를 대상으 로 과제를 통한 마음이론과 언어능력을 측정하였으며, 어머니 가 유아의 마음이론에 대해 보고하였다. 연구대상의 사회인 구학적 특성을 살펴보면, 먼저 성별은 남아 34 명 $(58.6 \%)$, 여아 24 명(41.4\%)으로 남아의 비율이 높았다. 평균 월령은 65.34 개

Table 1

Model Fit Indices of Study 1

\begin{tabular}{lcccccc}
\hline \multicolumn{1}{c}{ Model } & \multicolumn{1}{c}{$\chi^{2}$} & $d f$ & $\chi^{2} / d f$ & TLI & CFI & RMSEA \\
\hline 1 factor & $929.56^{* * *}$ & 710 & 1.30 & .92 & .94 & $.04(.03 \sim .04)$ \\
6 factors & $1356.26^{* * *}$ & 700 & 1.92 & .77 & .81 & $.06(.06 \sim .07)$ \\
\hline
\end{tabular}

Note. $N=252$.

${ }^{* * *} p<.001$. 
월 $(S D=9.04)$ 로, 만 3세 2명 $(3.4 \%)$, 만 4세 14 명 $(24.2 \%)$, 만 5 세 25 명(43.1\%), 만 6세 17 명(29.3\%)이었다. 출생순위는 첫째 가 34 명(58.6\%)으로 가장 많았으며, 둘째가 24명(41.4\%)이었 다. 부모의 평균연령은 어머니가 38.22세 $(S D=3.90)$, 아버지 가 40.05세 $(S D=4.25)$ 였으며, 어머니와 아버지 모두 35-39세 가 29명(50.0\%)과 25명(43.2\%)으로 가장 높은 비율을 나타냈 다. 부모의 교육수준은 어머니와 아버지 모두 대졸이 각각 38 명(65.6\%)과 31명(53.5\%)으로 가장 많았다.

\section{연구도구}

연구 2에서는 수렴타당도를 확인하기 위하여 마음이론을 어 머니가 보고한 CSUS 와 유아의 과제 수행을 통해 두 가지 방 법으로 측정하였다. 또한 공인타당도를 측정하기 위하여 유아 의 언어능력을 평가하는 수용·표현 어휘력 검사(REVT)를 사 용하였다.

\section{마음이론 척도}

마음이론을 측정하기 위하여 사용된 사회적 이해 척도(CSUS) 에 대한 설명은 연구 1 과 동일하다. CSUS의 전체 문항 간 내적 합치도(Cronbach's $\alpha$ )는 .91이었다.

\section{마음이론 과제}

CSUS의 하위요인에 해당하는 마음상태를 측정하기 위해 총 8 개의 과제를 사용하였다. 과제에는 Tahiroglu 등(2014)의 연 구에서 사용된 지식접근과제(Wellman \& Liu, 2004), 내용교체 과제(Wellman \& Liu, 2004), 이차조망수용과제(Flavell, Everett, Croft, \& Flavell, 1981), 외양실제과제(Flavell, Green, \& Flavell, 1986)가 포함되었으며, 이에 더해 의도(Gopnik \& Slaughter, 1991), 바람(Wellman \& Liu, 2004) 및 정서(Wellman \& Liu, 2004)를 측정하는 과제, 그리고 틀린믿음을 측정하는 대표적 인 과제인 위치이동과제(Wimmer \& Perner, 1983)가 포함되었 다. 각 과제를 살펴보면, 지식접근과제에서는 상자 안에 무엇 이 들어있는지 알고 있는 유아가 상자 안의 내용물을 보지 못 한 유아의 지식을 올바르게 판단하는지 측정한다. 내용교체 과제와 위치이동과제는 틀린믿음을 이해하는지 살펴보는 과 제로, 내용교체과제에서는 내용물이 무엇인지 명백히 드러나 는 상자 안에 기대하지 않았던 물건이 들어있는 것을 본 유아 가 상자 안을 보지 못한 유아의 틀린믿음을 아는지 살펴보고,
위치이동과제에서는 상자 안에 있는 물건이 다른 곳으로 옮겨 진 것을 본 유아가 그것을 보지 못한 다른 유아의 틀린믿음을 아는지 여부를 측정한다. 이차조망수용과제는 책상 위에 놓여 있는 그림이 자신의 반대편에 있는 사람에게는 위아래가 거꾸 로 보인다는 것을 아는지, 외양실제과제는 겉보기가 헛갈리는 물체에 대해 진짜와 가짜 구분을 할 수 있는지 여부를 살펴보 는 과제이다. 의도과제는 처음 의도했던 바와 결과가 다를 수 있음을 아는지 측정하는 과제이며, 바람과제는 타인이 자신과 다른 바람을 가질 수 있음을 아는지 살펴보는 과제이다. 마지 막으로 정서과제는 믿음이 틀렸다는 것을 인식했을 때의 기분 을 유아가 아는지 여부를 측정하는 과제이다. 전체 8 개의 과제 들은 소품을 달리하여 2회씩 수행되었으며, 각 과제당 점수의 범위는 0-2점이었다. 전체 과제들의 합계점수를 분석에 사용 하였고, 따라서 전체 점수의 범위는 0-16점이었다.

\section{언어능력}

유아의 언어능력을 측정하기 위하여 수용표현 어휘력검사를 사용하였다(Kim, Hong, Kim, Jang, \& Lee, 2009). 이 검사는 생 후 30 개월부터 성인기까지의 수용어휘능력과 표현어휘능력 을 측정하는 검사로, 대상자의 어휘발달수준을 백분위 점수로 환산하고 같은 연령대의 대상자들과 비교하여 상대적으로 어 느 정도의 어휘가 발달되었는지를 제시한다.

\section{연구절차}

연구 2의 연구대상은 경기도에 위치한 유치원 한 곳에서 2018 년 10-11월에 모집하였다. 어머니 대상 질문지는 가정으로 배 부되었으며, 유아 대상 실험은 유치원의 조용한 방에서 실험자 와 유아가 1:1로 실시하였다. 마음이론 과제와 언어평가는 각 각 20 분 이내로 소요되었으며, 유아의 피로감과 부담감을 줄 이기 위해 과제와 평가는 각기 다른 날 진행하였다. 실험 순서 는 무작위로 하여 $50 \%$ 의 유아에게는 마음이론 과제를, 나머지 $50 \%$ 의 유아에게는 언어능력 평가를 먼저 실시하였다. 마음이 론 과제 내에서의 순서는 선행연구(Wellman \& Liu, 2004)를 근 거로 가장 쉬운 과제인 바람 과제를 먼저 실시하여 유아가 실 험에 적응할 수 있도록 하였다. 이후 과제들은 과제의 순서를 체계적으로 변동시키는 역균형화(counterbalancing)를 하여 순 서효과가 과제들에 걸쳐 동등하게 작용하도록 하였다. 60 명의 유아 중 2 명의 유아가 언어평가에 참여하지 않아 최종적으로 58 명의 유아와 그들의 어머니가 연구에 참여하였다. 
Table 2

CSUS-Task Correlations

\begin{tabular}{|c|c|c|c|}
\hline Variables & CSUS & $M$ & $S D$ \\
\hline ToM composite & $.26^{*}$ & 13.18 & 3.21 \\
\hline Knowledge & .04 & 1.85 & .52 \\
\hline Belief & $.31^{*}$ & 1.49 & .67 \\
\hline Perception & .15 & 1.74 & .52 \\
\hline Desire & .09 & 1.82 & .50 \\
\hline Intention & .12 & 1.58 & .70 \\
\hline Emotion & $.26^{*}$ & 1.47 & .85 \\
\hline
\end{tabular}

Note: $N=58$; ToM = theory of mind; Belief = average of contents false belief and location false belief; Perception = average of Level-2 perspective taking and appearance-reality.

${ }^{*} p<.05$.

Table 3

Correlations Between CSUS and Verbal Ability

\begin{tabular}{llll}
\hline \multicolumn{1}{c}{ Variables } & CSUS & $M$ & $S D$ \\
\hline Verbal ability & & & \\
Expressive vocabulary & $.22 \dagger$ & 68.78 & 11.47 \\
Receptive vocabulary & .16 & 64.35 & 12.05 \\
\hline
\end{tabular}

Note. $N=58$.

$\dagger p<.10$.

\section{자료분석}

수집된 자료는 SPSS 21.0 (IBM Co., Armonk, NY)을 사용하여 기술통계, 신뢰도 분석, 상관분석을 통해 분석되었다. 먼저 기 술통계를 통해 연구대상의 일반적인 특성을 살펴보았고, 신뢰 도 분석을 위해 전체 문항의 내적합치도를 산출하였다. 마지 막으로, 척도를 통해 측정한 마음이론과 과제를 통해 측정한 마음이론 간의 상관분석을 실시하여 구인타당도 중 수렴타당 도를 검증하였으며, CSUS와 언어능력과의 상관분석을 실시 하여 공인타당도를 검증하였다.

\section{Results}

\section{수렴타당도 검증}

수렴타당도의 검증을 위해 과제를 통해 측정한 마음이론과 CSUS를 사용하여 측정한 마음이론 간의 상관을 살펴보았다. 개별 과제 중 내용교체과제와 위치이동과제의 점수의 평균을 틀린믿음의 점수로 사용하고, 이차조망수용과제와 외양실제 과제의 점수의 평균을 지각의 점수로 사용하였다. 분석 결과,
CSUS와 마음이론 과제합계 간의 상관이 정적으로 유의하여 $(r=.26, p<.05)$ CSUS의 수렴타당도가 확인되었다(Table 2). CSUS와 개별 과제들 간의 관계를 살펴보면, CSUS와 믿음 $(r=$ $.31, p<.05)$ 및 정서과제 $(r=.26, p<.05)$ 사이에 유의한 상관 이 나타났다.

\section{공인타당도 검증}

공인타당도의 검증을 위해 언어능력과 CSUS 간의 상관을 분 석하였다. 그 결과(Table 3), CSUS와 수용어휘능력 점수와의 상관은 유의하지 않았으나, 표현어휘능력과의 상관은 유의 수준에 근사하였다 $(r=.22, p<.10)$. 선행연구들에서 마음이 론과 언어능력 간의 정적 상관이 일관적으로 보고된다는 점 (Astington \& Baird, 2005; Bartsch \& Wellman, 1995; DeVilliers, 2007; Milligan et al., 2007)에 근거하여 일방향 검정을 실시하 였을 경우에는 두 변인 간 상관이 유의하였다 $(r=.22, p<.05)$.

\section{[연구 3]}

연구문제1

마음이론 척도의 교차타당도와 공인타당도는 어떠한가? 


\section{Methods}

\section{연구대상}

연구 3에는 만 3-6세의 유아와 어머니 220쌍이 참여하였고, 어 머니가 유아의 마음이론과 실행기능, 그리고 자신의 양육행동 에 대해 보고하였다. 연구 1 에서 확인된 모형의 교차타당도를 확보하기 위하여 연구 1 과 다른 새로운 표본을 대상으로 자료 를 수집하였다. 연구대상의 사회인구학적 특성을 살펴보면, 성 별은 남아 85명(38.6\%), 여아 135명(61.4\%)으로 여아의 비율이 더 높았다. 유아의 평균월령은 51.21 개월 $(S D=12.85)$ 이었으며, 연령은 만 3세 58명(26.4\%), 만 4세 60명(27.3\%), 만 5세 55명 (25.0\%), 만 6세 47명(21.3\%)이었다. 유아의 출생순위는 첫째 가 160 명 $(72.7 \%)$ 으로 가장 많았으며, 둘째가 45 명(20.5\%)이었 다. 부모의 평균연령은 어머니가 35.49세 $(S D=4.69)$, 아버지가 37.50 세 $(S D=5.12)$ 이었으며, 어머니와 아버지 모두 각각 35-39 세가 85명(38.6\%)과 91명(41.4\%)으로 가장 높은 비율을 나타 냈다. 부모의 교육수준은 어머니와 아버지 모두 각각 대졸이 125 명(56.8\%)과 151 명(68.6\%)으로 가장 많았다.

연구 1 과 연구 3 의 연구대상이 사회인구학적 특성에 차이 가 있는지 살펴보기 위해 범주형 변인인 성별, 출생순위, 부모 의 교육수준은 교차분석을, 연속형 변인인 유아의 연령, 부모 의 연령은 $t$ 검정을 실시하였다. 그 결과, 연구 1 과 연구 3 의 연 구대상 간 성별 분포에서 유의한 차이가 나타났는데 $\left(\chi^{2}(1)=\right.$ 7.94, $p$ <.01), 연구 1에는 남아(130명, 51.4\%)가, 연구 3에는 여아(135명, $61.4 \%)$ 가 더 많이 포함되었다. 그 외 출생순위, 부 모의 교육수준, 유아의 연령, 부모의 연령은 연구 1 과 연구 3 의 연구대상 간 유의한 차이를 보이지 않았다.

\section{연구도구}

연구 3은 CSUS의 교차타당도 및 공인타당도를 검증하기 위하 여 어머니 보고를 통해 유아의 마음이론과 실행기능 및 어머 니의 양육행동을 측정하였다.

\section{마음이론}

마음이론을 측정하기 위해 사용된 사회적 이해 척도(CSUS)에 대한 설명은 연구 1 에 제시된 것과 동일하다. CSUS의 전체 문 항 간 내적합치도는 .86이었다.

\section{실행기능}

유아의 실행기능은 Gioia 등(2003)이 개발한 유아용 실행기능 행동평정척도(Behavior Rating Inventory of Executive FunctionPreschool version [BRIEF-P])를 Seo와 Park (2011)이 번안한 척 도를 사용하여 측정하였다. BRIEF-P는 신뢰도와 타당도가 입 증된 척도로(Isquith, Gioia, \& Espy, 2004), 유아기 실행기능을 측정하는 데 널리 사용되고 있다. 또한 마음이론과 관련성이 높은 것으로 보고된 억제통제나 작업기억(Carlson et al., 2002; Perner et al., 2002)과 같은 하위요인을 포함하고 있기 때문에 CSUS의 공인타당도를 검증하기 위한 척도로 사용하였다.

BRIEF-P는 총 63문항이며, 억제, 전환, 감정조절, 작업기억, 계획 및 조직화의 5 개 하위요인으로 구성된다. 문항의 예를 살 펴보면, 억제(16문항)는 “잠시도 가만히 있지 못한다.”, 전환(10 문항)은 “활동을 바꾸는 것을 어려워한다.”, 감정조절(10문항) 은 "너무 쉽게 화를 낸다.", 작업기억(17문항)은 "두 가지 일을 주면, 한 가지만 기억한다.", 계획 및 조직화(10문항)는 “청소를 하라고 지시하면, 물건들을 두서없이 비조직적으로 치운다.” 등 을 들 수 있다. 모든 문항은 5점 Likert식 척도로 구성되었으며, 점수가 높을수록 실행기능이 낮은 것으로 서술되어 있어 모든 문항을 역코딩한 후 평균을 산출하였다. 따라서 점수가 높을수 록 실행기능이 높으며, 실행기능의 전체 내적합치도(Cronbach's $\alpha$ )는 . 97 이었고, 각 하위요인별 내적합치도는 억제 . 91 , 전환 .85, 감정조절 .87 , 작업기억 .92 , 계획 및 조직화 .83 이었다.

\section{양육행동}

양육행동의 측정을 위해 Rhee (2012)가 개발한 저학년 부모용 양육행동 척도를 $\mathrm{Na}$ (2012)가 유아기를 대상으로 수정한 척도 를 사용하였다. 본 척도는 총 45 문항으로 온정, 논리적 설명, 개입, 강압, 방임의 5 개 하위요인으로 구성된다. 문항의 예로 는 온정(9문항)은 “아이에게 다정하고 부드러운 목소리로 말 을 한다.”, 논리적 설명(10문항)은 “아이가 한 잘못된 행동의 결과에 대해 설명해 준다.", 개입(9문항)은 "아이가 하는 일을 잠자코 보지 못하고 간섭을 한다.”, 강압(7문항)은 “이유를 설 명하기 보다는 벌로써 아이를 지도한다.”, 방임(10문항)은 “아 이에 대해 관심이 없어서 칭찬하거나 혼내는 일이 없다.” 등이 있다. 모든 문항은 4점 Likert식 척도로 응답되며, 점수가 높을 수록 각 하위요인의 특성이 높음을 의미한다. 각 하위요인의 내적합치도(Cronbach's $\alpha$ )는 온정 .82 , 논리적 설명 .82 , 개입 .90 , 강압 .90 , 방임 .94 이었다. 
Table 4

Model Fit Indices of Study 3

\begin{tabular}{lcccccc}
\hline \multicolumn{1}{c}{ Model } & $\chi^{2}$ & $d f$ & & & & RMSEA \\
\hline 1 factor & $896.83^{* * *}$ & 699 & 1.38 & .90 & CFI & $($ LO90 HI90) \\
\hline $\begin{array}{l}\text { Note. } N=220 . \\
{ }^{* * *} p<.001 .\end{array}$ & & & & & $.04(.03 \sim .04)$ \\
\hline
\end{tabular}

Table 5

Correlations Among CSUS, Executive Function and Parenting Behaviors

\begin{tabular}{llll}
\hline \multicolumn{1}{c}{ Variables } & CSUS & $M$ & $S D$ \\
\hline Executive function & $.19^{* *}$ & 3.43 & .68 \\
Inhibit & $.21^{* *}$ & 3.47 & .74 \\
Shifting & .10 & 3.40 & .73 \\
Emotional control & .03 & 3.46 & .72 \\
Working memory & $.27^{* * *}$ & 3.42 & .70 \\
Planning/Organizing & $.20^{* *}$ & 3.41 & .70 \\
Parenting behaviors & & & \\
Warmth & $.29^{* * *}$ & 3.06 & .40 \\
Logical reasoning & $.46^{* * *}$ & 3.10 & .36 \\
Intrusiveness & .12 & 2.21 & .55 \\
Coercion & .02 & 1.95 & .62 \\
Neglect &. .00 & 1.39 & .53 \\
\hline
\end{tabular}

Note. $N=220$.

${ }^{* *} p<.01 .{ }^{* * *} p<.001$.

연구절차

연구 3의 연구대상은 2018년 10월 온라인조사기관을 통해 모 집되었다. 만 3-6세 유아기 자녀를 둔 어머니 220명이 마음이 론, 실행기능 및 양육행동에 대한 설문에 응답하였으며, 총 150 문항의 응답에 소요되는 시간은 20-30분이었다.

\section{자료분석}

연구대상의 일반적인 특성과 평균 및 표준편차를 알아보기 위 해 기술통계분석을 실시하였고, 신뢰도 분석을 위해 내적합치 도(Cronbach's $\alpha$ )를 산출하였다. 교차타당도 검증을 위해 확인 적 요인분석을 실시하였으며, 준거관련 타당도 중 공인타당도 의 검증을 위해 CSUS와 실행기능 및 양육행동과의 상관분석 을 실시하였다.

\section{Results}

\section{교차타당도 검증}

연구 3 에서는 확인적 요인분석을 통해 연구 1 에서 검증된 모 형이 연구 3 의 새로운 대상에게 적용되는지 확인함으로써 교 차타당도를 검증하였다. 그 결과, 연구 1 의 단일요인 모형의 적합도가 양호하게 나타났다. 연구 3의 모형의 적합도 지수 (Table 4)는 $\chi^{2}(699)=896.83(p<.001), \chi^{2} / d f=1.38, T L I=.90$, $\mathrm{CFI}=.92, \mathrm{RAMEA}=.04(90 \% \mathrm{CI}[.03, .04])$ 로 적절한 수준이 었으며, 이로써 연구 1 의 모형이 새로운 대상에게도 적합하다 는 것이 확인되어 교차타당도가 검증되었다.

\section{공인타당도 검증}

공인타당도의 검증을 위해 CSUS로 측정한 유아의 마음이론 이 유아의 실행기능 및 어머니의 양육행동과 상관이 있는지 분석하였다(Table 5). 그 결과, 마음이론과 실행기능 간의 상관 
은 정적으로 유의하였으며 $(r=.19, p<.01)$, 마음이론은 실행 기능의 하위요인 중 억제 $(r=.21, p<.01)$, 작업기억 $(r=.27, p<$ $.001)$, 계획 및 조직화 $(r=.20, p<.01)$ 와 유의한 상관을 보였다. 다음으로 유아의 마음이론과 어머니의 양육행동 간의 상관관 계를 분석한 결과, 마음이론은 어머니의 양육행동 중 긍정적 양육행동에 포함되는 온정 $(r=.29, p<.001)$ 및 논리적 설명 $(r$ $=.46, p<.001)$ 과 유의한 정적 상관을 보였다. 이를 볼 때, 긍 정적 양육행동이 전반적인 마음이론에 미치는 영향이 큰 것을 알 수 있다.

\section{Discussion}

본 연구는 만 3-6세 유아의 마음이론을 평가하기 위해 국외에 서 개발된 사회적 이해 척도(CSUS)의 신뢰도와 타당도를 국내 유아를 대상으로 검증함으로써 척도의 심리측정적 특성을 확 인하는 것을 목적으로 하였다. 이를 위해 세 가지 연구를 구성 하였는데, 연구 1 에서는 CSUS의 내용타당도와 함께 확인적 요 인분석을 통한 구인타당도와 신뢰도를 검증하였다. 연구 2에 서는 유아의 마음이론을 CSUS와 과제를 통해 측정하고 그 상 관을 살펴봄으로써 구인타당도 중 하나인 수렴타당도를 검증 하였다. 또한 CSUS와 언어능력 간의 상관을 살펴봄으로써 준 거관련 타당도 중 하나인 공인타당도를 검증하였다. 연구 3에 서는 연구 1 에서 결정된 모형을 새로운 대상에게 반복 검증함 으로써 교차타당도를 확인하였으며, CSUS를 통해 측정한 마 음이론과 실행기능 및 양육행동 간의 상관을 분석함으로써 공 인타당도를 검증하였다. 세 연구를 통해 확인된 CSUS의 신뢰 도와 타당도에 대한 결론을 요약하고 논의하면 다음과 같다.

첫째, CSUS의 내용타당도를 확인하기 전 번역-역번역 과 정을 통해 원척도와 동일한 의미를 가지도록 척도를 완성하였 으며, 이후 국문학자의 감수를 통해 표현과 문법을 교정하여 자연스럽게 읽히면서도 정확한 문장이 되도록 하였다. 이러한 과정을 통해 완성된 문항들에 대해 네 명의 아동학 및 유아교 육 전문가가 문항의 명확성 및 내용의 적절성 등을 평가하였 고, 그 결과를 바탕으로 문항을 수정하였다. 이를 통해 각 문항 이 측정하고자 하는 마음상태를 잘 반영하고 있는지 확인하여 전문가의 판단에 의한 내용타당도를 확보하였다.

둘째, 구인타당도 검증을 위해 확인적 요인분석을 실시한 결과, 원척도를 개발한 연구(Tahiroglu et al., 2014) 및 이를 타 당화한 연구(Smogorzewska et al., 2019)에서처럼 단일요인 모 형이 적절한 적합도를 가지고 있는 것으로 확인되어 CSUS의
구인타당도가 검증되었다. 반면, 6 요인 모형은 적절한 적합도 를 보이지 않아 CSUS의 문항은 하위요인별로 구분되기보다 는 전체가 마음상태에 관한 하나의 요인으로 수렴하는 것으 로 나타났다. 이는 하위요인 간의 관계에 기인하는 것으로 보 이는데, 마음이론을 구성하는 마음상태들은 의도가 바람과 행동을 중재하며(Wellman, 1992), 지각은 지식의 원천(Pratt \& Bryant, 1990)이 되는 것과 같이 상호 영향을 미치며 서로 인과 관계(Wellman, 1992)를 갖기 때문에 마음이론을 총체적으로 바라보는 것이 적합할 것이다. CSUS가 하위요인별로 구분되 지 않는 것에 대한 또 다른 원인은 과제와 구별되는 척도의 문 항의 특징에서 찾아볼 수 있다. 마음이론 과제는 각 능력을 측 정하기 위해 고안한 개별 과제들을 통해 유아의 수행을 측정 하기 때문에 각각의 과제에서 측정하고자 하는 능력 간 구분 이 명확할 수 있다. 반면, CSUS는 문항들이 유아의 마음이론 을 평가하는 일상적인 행동, 의사소통 및 사회적 상호작용 등 을 나타내고 있는데, 이러한 문항들은 하나의 하위요인에 명 확히 구분되기 어려울 수 있다. 예를 들어, 지식에 대한 이해를 측정하는 문항인 “숨바꼭질을 잘 한다.”는 놀이에서 시각적이 나 청각적 정보가 지식이 될 수 있음을 아는 것으로 해석될 수 있고, 다른 한편으로는 사람들의 지각적 주의를 유도하지 않 도록 행동하는 능력과도 연결 될 수 있으므로 지각에 대한 이 해와 연결될 수도 있다. 따라서 CSUS는 마음이론을 평가하는 다양한 문항들을 통해 마음이론을 폭넓게 평가하는 것을 가능 하게 하지만(Tahiroglu et al., 2014), 하나의 문항이 복수의 하위 요인들의 개념을 반영할 수 있으므로 각 문항이 하나의 하위 요인에만 명확하게 적재되지는 않을 수 있다. 이러한 결과를 볼 때, CSUS는 원척도(Tahiroglu et al., 2014)나 선행된 타당화 연구(Smogorzewska et al., 2019)에서 제안한 것처럼 국내에서 도 단일요인으로 사용하는 것이 적합할 것으로 보인다.

셋째, 최종 척도에 대한 신뢰도를 산출한 결과, CSUS의 전 체 신뢰도는 세 연구에서 .86 .91로 나타나 우수한 내적합치 도를 보였으며, 3주 간격으로 시행된 검사-재검사 신뢰도 또 한 .74로 양호하였다. 이는 원척도(Tahiroglu et al., 2014) 및 타 당화 연구들(Bia ł ecka-Pikul \& Stępień-Nycz, 2019; BrosseauLiard \& Poulin-Dubois, 2019; Smogorzewska et al., 2019)에서 보 고된 신뢰도 계수와 유사한 수준이다. 또한 과제를 사용한 연 구들(Blijd-Hoogewys et al., 2008; Hughes et al., 2000)과 비교해 보아도 본 척도의 신뢰도는 적합한 것으로 보인다.

넷째, CSUS 점수와 마음이론 과제 간 유의한 상관이 나타 나 구인타당도 중 하나인 수렴타당도가 입증되었다. 두 점수 간 유의한 상관이 나타났으나 그 정도는 그리 높지 않았는데, 
다양한 정보제공자를 통해 측정한 점수 간의 상관은 단일 정 보제공자가 보고한 점수 간 상관보다 약할 수 있다. 유사한 선 행연구에서도 아동의 충동성이나 억제통제에 있어 부모보 고와 아동의 수행 간의 상관이 높지 않게 나타난 것을 볼 때 (Carlson \& Moses, 2001; Kochanska et al., 1996), CSUS 점수와 마음이론 과제합계 간에 유의한 상관이 나타난 것은 의미있게 볼 수 있다.

다섯째, 마음이론과 관련이 있는 것으로 알려진 언어능력, 실행기능 및 어머니의 양육행동과 CSUS를 통해 측정한 마음 이론 간의 관련성을 살펴봄으로써 공인타당도를 검증하였다. 그 결과, 언어능력의 경우 CSUS와 상관이 유의하지 않았지만, 실행기능과 양육행동의 경우 CSUS와 유의한 상관을 보여 실 행기능과 양육행동을 준거로 한 공인타당도가 입증되었다. 각 각을 살펴보면, 언어능력의 경우 CSUS와 유의한 상관을 보이 지는 않았지만 표현어휘능력은 유의 확률이 .09로 나타나 유 의수준에 근접하였다. 과제를 통해 마음이론을 측정한 선행 연구들(Astington \& Jenkins, 1999; DeVilliers, 2007)이 언어능 력과 정적 상관을 보고한 것에 근거하여 일방향분석을 실시한 결과, CSUS와 언어능력 간 유의한 상관이 나타났다 $(r=.22, p$ $<.05)$. 이러한 결과를 볼 때, CSUS와 언어능력 간 상관이 유의 하지 않은 것은 연구대상의 수가 적기 때문일 가능성이 있으 므로 후속 연구에서는 연구대상의 수를 확대하여 둘 간의 관 계를 연구해 볼 필요가 있다. 또 다른 원인으로 본 연구에서는 어머니가 유아의 마음이론에 대해 평가하였는데, 어머니는 유 아가 자신의 마음이론을 언어로 표현하는 것뿐 아니라 일상생 활에서 비언어적으로 표현하는 것을 관찰할 수 있기 때문일 수 있다. 예를 들어, 척도의 문항은 언어로 표현되는 '이야기한 다' 뿐만 아니라 ‘행동한다', '할 수 있다', '고려한다' 등 여러 비 언어적으로 표현되는 행동이나 능력들을 포함한다. 따라서 어 머니는 비언어적으로 표현되는 유아의 마음이론까지 폭넓게 파악하여 보고할 수 있으므로 유아의 언어능력과 CSUS 간의 상관이 유의하지 않게 나타난 것일 수 있다. 이외에도 CSUS는 어머니를 통해 보고되었으므로 측정방법에 유아의 언어의 영 향이 적을 수 있다. 이에 반해, 마음이론 과제는 유아가 실험자 의 언어를 이해해야 하며, 언어로 자신의 마음이론을 표현해 야 하므로 측정방법에 언어적 요소가 더 크게 영향을 미칠 수 있을 것으로 해석해볼 수 있다.

다음으로 CSUS는 실행기능과 유의한 상관을 보였으며, 이 를 통해 준거관련 타당도인 공인타당도를 입증하였다. 척도 를 통해 얻어진 마음이론 점수가 실행기능의 하위요인 중 억 제, 작업기억, 계획 및 조직화와 유의한 상관관계를 보인 것은
과제를 통해 측정한 마음이론이 억제나 작업기억(Carlson \& Moses, 2001; Carlson et al., 2002; Perner et al., 2002)과 상관관계 가 있음을 밝힌 선행연구들을 지지하는 결과이다. CSUS는 실 행기능의 하위요인 중 작업기억과 상관이 가장 높게 나타났는 데, 작업기억은 정보들을 일시적으로 유지하며 처리하는 능력 이므로 상반된 시각을 유지해야하는 마음이론과 관련될 수 있 다(Carlson et al., 2002; Gordon \& Olson, 1998). 그 수는 적지만 척도를 통해 얻어진 마음이론 점수와 실행기능 간의 관계를 밝힌 연구들(Jang \& Shin, 2018; Tahiroglu et al., 2014)이 일부 보고되었으며 본 연구는 이러한 연구들과도 유사한 결과를 보 인다.

이어서, CSUS의 공인타당도를 검증하기 위해 어머니의 양 육행동이 유아의 마음이론과 관계가 있는지 살펴본 결과, 어 머니가 온정적인 양육행동을 보이고, 논리적 설명을 할수록 유아의 마음이론이 높은 것으로 나타났다. 이는 CSUS를 사용 하여 측정한 마음이론과 양육행동 간의 관계를 살펴본 선행 연구의 결과와 일치하는데, Jang과 Shin (2018)은 어머니의 온 정 및 논리적 설명과 유아의 마음이론 간의 관계를 밝혔으며, Smogorzewska 등(2019)은 부모가 온정, 지지, 추론 등으로 표 현되는 민주적 양육을 할수록 유아의 마음이론이 높음을 밝 혔다. 과제를 통해 마음이론을 측정한 선행연구들도 부모가 민주적 양육을 할수록 마음이론이 높은 것으로 보고하였다 (O'Reilly \& Peterson, 2014). 이처럼 높은 온정성과 반응성을 보 이고, 세상에 대한 관점이나 타인에 대한 관점을 반영해 볼 기 회를 주는 긍정적인 양육은 자녀의 마음이론을 촉진하는 것으 로 제안되고 있으며(Ruffman et al., 1999), 어린 자녀와 친밀한 상호작용을 하는 어머니의 양육태도는 자녀의 마음이론 발달 에도 핵심적인 역할을 담당함을 알 수 있다(Bae \& Choi, 2002).

마지막으로, 교차타당도를 검증하기 위해 연구 1 에서 적 합성이 확인된 모형이 연구 3 의 새로운 집단에게 적용되는지 살펴보았다. 그 결과, Tahiroglu 등(2014)과 Smogorzewska 등 (2019)의 연구와 동일하게 단일요인으로 검증된 연구 1 의 모 형이 연구 3 의 대상에게도 적합한 것으로 나타나 교차타당도 가 검증되었다.

본 연구의 결과를 바탕으로 CSUS의 사용에 대해 제안하 면, 먼저 마음상태의 여러 측면을 평가하도록 구성된 42 문 항을 단일요인으로 사용하여 전반적인 마음이론을 측정하 는 것이 적절할 것으로 보인다. 타문화권에서 실시된 연구들 (Smogorzewska et al., 2019; Tahiroglu et al, 2014) 또한 단일요인 모형을 지지하므로, 동일한 문항과 모형으로 구성된 척도는 비교문화연구 시 그 활용 가능성이 높을 것이다. 다음으로 원 
저자(Tahiroglu et al, 2014)가 제안한 바와 같이 CSUS를 통해 측정한 점수를 유아의 마음이론에 대한 절대지수로 삼는 것보 다 CSUS를 마음이론 과제를 보완하는 도구로 활용하는 것이 더 적절할 것으로 보이며, 다른 발달의 측면들과의 관계를 살 펴보거나 종단연구 등에 활용할 수 있을 것으로 기대한다.

본 연구의 제한점과 함께 후속연구를 위한 제언을 하면 다 음과 같다. 첫째, 연구대상의 범위 측면에서 볼 때 연구 2 의 경 우 실험을 위한 대상자의 모집범위가 유치원 한 곳으로 제한 되어 있어 다양한 표본을 반영하지 못하였다는 한계가 있다. 특히 연구 2 의 부모의 학력의 경우, 어머니와 아버지는 대졸 이상이 각각 $87 \%$ 와 $93.1 \%$ 로 높은 수준을 보였다. 따라서 연 구에 다양한 대상을 포함하여 CSUS가 폭 넓게 적용될 수 있는 척도인지 평가하는 것이 필요하다. 둘째, 본 연구는 조사 설계 에 있어 제한점을 갖는데, 유아의 마음이론에 영향을 미칠 가 능성이 있는 어머니의 주양육자 여부, 취업여부, 소득수준 등 을 포함하지 못하였다. 따라서 후속연구에서는 유아의 마음이 론에 영향을 줄 수 있는 보고자의 정보에 대한 고려가 필요할 것이다. 셋째, 연구대상을 확대하여 연령별로 충분한 수의 집 단을 대상으로 한다면, 연령에 따른 분석과 함께 하위요인의 사용 가능성에 대한 추가적인 연구가 가능할 것이며, CSUS를 더 의미있게 사용할 수 있는 근거들을 산출할 수 있을 것이다.

이러한 제한점에도 본 연구는 다음과 같은 의의를 갖는다. 먼저 CSUS의 신뢰도와 타당도를 확인함으로써 국내 유아의 마음이론을 보다 손쉽게 측정할 수 있는 추가적인 도구를 제 공하였다. 본 연구에서 타당화한 CSUS는 비언어적으로 표 현될 수 있는 유아의 마음이론을 측정에 포함시켜 기억이나 언어적인 요소의 영향을 받을 수 있는 과제의 제한점(Happé, 1995)을 보완할 수 있을 것이다. 둘째, 마음이론의 비교문화 연구에 사용 가능한 척도를 제공하였다는데 의의가 있다. 유 아기 마음이론은 양육행동과 같은 관련 변인들과의 관계에서 문화권에 따라 다른 양상을 보여(Vinden, 2001) 비교문화연구 의 필요성이 제안되고 있으므로(Sabbagh et al., 2006) 여러 문 화권에서 타당화된 척도는 변인들 간의 관계에서 발생할 수 있는 문화적 차이를 연구하는 데 도움이 될 수 있을 것이다. 셋 째, CSUS의 수렴타당도를 검증하는 데 있어 척도의 하위요인 을 아우르는 다양한 마음이론 과제를 사용하였으며, 이를 통 한 과제의 합계가 CSUS와 유의함을 밝혀 CSUS가 마음이론 의 의미를 포괄적으로 측정하고 있음을 확인하였다. 마지막으 로, 공인타당도 검증 시 개인적 변인과 환경적 변인을 동시에 고려하여 다각적인 측면에서 변인과의 관계를 탐색하였다. 향 후 타당성에 대한 검증을 거친 CSUS가 유아의 마음이론 연구
에 효용성이 높은 도구로 활용되어 연구의 활성화에 기여하며 이를 통해 국내 유아의 사회인지 증진을 위한 효과적인 개입 의 방향을 모색하는데 도움이 될 수 있기를 기대한다.

\section{Acknowledgements}

This work was supported by the Ministry of Education of the Republic of Korea and the National Research Foundation of Korea (NRF-2016S1A3A2924375).

\section{Notes}

This article is a part of the first author's doctoral dissertation submitted in 2019, and was presented at the 2019 Annual Fall Conference of the Korean Association of Child Studies.

\section{Conflict of Interest}

No potential conflict of interest relevant to this article was reported.

\section{Ethics Statement}

All procedures of this research were reviewed by IRB (162-17) and (162-18).

\section{References}

\section{In English}

Astington, J. W., \& Baird, J. A. (2005). Introduction: Why language matters. In J. W. Astington \& J. A. Baird (Eds.), Why language matters for theory of mind (pp. 3-25). New York: Oxford University Press.

Astington, J. W., \& Jenkins, J. M. (1999). A longitudinal study of the relation between language and theory-of-mind development. Developmental Psychology, 35(5), 1311-1320. doi:10. 1037/0012-1649.35.5.1311

Bartsch, K., \& Wellman, H. M. (1995). Children talk about the 
mind. New York: Oxford University Press.

Besiroglu, B., Selcuk, B., \& Tahiroglu, D. (2017, April). The psychometric properties of the Children's Social Understanding Scale-Short form among children with Autism Spectrum Disorders. Poster presented at Society for Research in Child Development Conference, Austin, TX.

Białecka-Pikul, M., \& Stępień-Nycz, M. (2019). Parent-report measure of theory of mind: Adaptation to polish of the Children's Social Understanding Scale. European Journal of Developmental Psychology, 16(3), 318-326. doi:10.1080/17 405629.2017.1406850

Blair, C., \& Razza, R. P. (2007). Relating effortful control, executive function, and false belief understanding to emerging math and literacy ability in kindergarten. Child Development, 78(2), 647-663. doi:10.1111/j.1467-8624.2007.01019.x

Blijd-Hoogewys, E. M. A., van Geert, P. L. C., Serra, M., \& Minderaa, R. B. (2008). Measuring theory of mind in children. Psychometric properties of the ToM storybooks. Journal of Autism and Developmental Disorders, 38(10), 1907-1930. doi:10.1007/s10803-008-0585-3

Brosseau-Liard, P., \& Poulin-Dubois, D. (2019). Reliability and validity of the French adaptation of the Children's Social Understanding Scale. Psychologie Francaise, 64(4), 331-341. doi:10.1016/j.psfr.2018.01.003

Carlson, S. M., \& Moses, L. J. (2001). Individual differences in inhibitory control and children's theory of mind. Child Development, 72(4), 1032-1053. doi:10.1111/1467-8624.00333

Carlson, S. M., Moses, L. J., \& Breton, C. (2002). How specific is the relation between executive function and theory of mind? Contributions of inhibitory control and working memory. Infant and Child Development, 11(2), 73-92. doi:10.1002/icd.298

DeVilliers, J. (2007). The interface of language and theory of mind. Lingua, 117(11), 1858-1878. doi:10.1016/j.lingua. 2006.11.006

DeVellis, R. F. (2016). Scale development: Theory and applications (2nd ed.). In SAGE (Series Ed.), Applied Social Research Methods (Vol. 26). Thousand Oaks, CA: Sage.

Dunn, J., \& Brown, J. R. (1993). Early conversations about causality: Content, pragmatics and developmental change. British Journal of Developmental Psychology, 11(2), 107-123. doi:10.1111/j.2044-835X.1993.tb00591.x

Flavell, J. H., Everett, B. A., Croft, K., \& Flavell, E. R. (1981). Young children's knowledge about visual perception: Further evidence for the level 1-level 2 distinction. Developmental Psychology, 17(1), 99-103. doi:10.1037/0012-1649.17.1.99

Flavell, J. H., Green, F. L., \& Flavell, E. R. (1986). Development of knowledge about the appearance-reality distinction. Monographs of the Society for Research in Child Development, 51(1), 1-87. doi:10.2307/1165866
Flavell, J. H., Miller, P. H., \& Miller, S. A. (1993). Cognitive development (3rd ed.). Englewood Cliffs, NJ: Prentice-Hall.

Gioia, G. A., Espy, K. A., \& Isquith, P. K. (2003). BRIEF-P: Behavior rating inventory of executive function-preschool version: Professional manual. Odessa, FL: Psychological Assessment Resources.

Gluck, S. Ch., Paik, J., Duh, S., Moses, L., \& Nelson, J. T. (2017, April). Reliability and validity of the Children's Social Understanding Scale in a Chinese sample. Poster presented at Society for Research in Child Development Conference, Austin, TX.

Gopnik, A., \& Slaughter, V. (1991). Young children's understanding of changes in their mental states. Child Development, 62(1), 98-110. doi:10.1111/j.1467-8624.1991.tb01517.x

Gordon, A. C. L., \& Olson, D. R. (1998). The relation between acquisition of a theory of mind and the capacity to hold in mind. Journal of Experimental Child Psychology, 68(1), 7083. doi:10.1006/jecp.1997.2423

Gradel, K., Thompson, M. S., \& Sheehan, R. (1981). Parental and professional agreement in early childhood assessment. Topics in Early Childhood Special Education, 1(2), 31-39. doi:10.1177/027112148100100208

Happé, F. G. E. (1995). The role of age and verbal ability in the theory of mind task performance of subjects with autism. Child Development, 66(3), 843-855. doi:10.1111/j.14678624.1995.tb00909.x

Hughes, C., \& Leekam, S. (2004). What are the links between theory of mind and social relations? Reviews, reflections and new directions for studies and atypical development. Social Development, 13(4), 590-619. doi:.10.1111/j.14679507.2004.00285.x

Hughes, C., Adlam, A., Happe, F., Jackson, J., Taylor, A., \& Caspi, A. (2000). Good test-retest reliability for standard and advanced false-belief tasks across a wide range of abilities. The Journal of Child Psychology and Psychiatry and Allied Disciplines, 41(4), 483-490. doi:10.1111/1469-7610.00633

Hutchins, T. L., Prelock, P. A., \& Bonazinga, L. (2012). Psychometric evaluation of the Theory of Mind Inventory (ToMI): A study of typically developing children and children with autism spectrum disorder. Journal of Autism and Developmental Disorders, 42, 327-341. doi:10.1007/ s10803-011-1244-7

Imuta, K., Henry, J. D., Slaughter, V., Selcuk, B., \& Ruffman, T. (2016). Theory of mind and prosocial behavior in childhood: A meta-analytic review. Developmental Psychology, 52(8), 1192-1205. doi:10.1037/dev0000140

Isquith, P. K., Gioia, G. A., \& Espy, K. A. (2004). Executive function in preschool children: Examination through everyday behavior. Developmental Neuropsychology, 26(1), 403-422. doi:10.1207/s15326942dn2601_3 
Kochanska, G., Murray, K., Jacques, T. Y., Koenig, A. L., \& Vandegeest, K. A. (1996). Inhibitory control in young children and its role in emerging internalization. Child Development, 67(2), 490-507. doi:10.1111/j.1467-8624. 1996.tb01747.x

Miller, S. A. (1986). Parents' beliefs about their children's cognitive abilities. Developmental Psychology, 22(2), 276-284. doi:10.1037/0012-1649.22.2.276

Milligan, K., Astington, J. W., \& Dack, L. A. (2007). Language and theory of mind: Meta-analysis of the relation between language ability and false-belief understanding. Child Development, 78(2), 622-646. doi:10.1111/j.1467-8624. 2007.01018.x

Nelson, J. T. (2017). A cross-cultural study of parental socialization of theory of mind (Master's thesis). Retrieved from http://sfsudspace.calstate.edu/handle/10211.3/196574

Newton, P., Reddy, V., \& Bull, R. (2000). Children's everyday deception and performance on false-belief tasks. British Journal of Developmental Psychology, 18(2), 297-317. doi:10.1348/026151000165706

Nunnally, J. C., \& Bernstein, I. (1994). Psychological theory (3rd ed.). New York: McGraw-Hill.

O'Reilly, J., \& Peterson, C. C. (2014). Theory of mind at home: Linking authoritative and authoritarian parenting styles to children's social understanding. Early Child Development and Care, 184(12), 1934-1947. doi:10.1080/03004430.20 14.894034

Perner, J., Lang, B., \& Kloo, D. (2002). Theory of mind and selfcontrol: More than a common problem of inhibition. Child Development, 73(3), 752-767. doi:10.1111/1467-8624. 00436

Pratt, C., \& Bryant, P. (1990). Young children understand that looking leads to knowing (so long as they are looking into a single barrel). Child Development, 61(4), 973-982. doi:10.1111/j.1467-8624.1990.tb02835.x

Prelock, P. A. (2006). Autism spectrum disorders: Issues in assessment \& intervention. Austin, TX: Pro-Ed Publishers.

Raver, C., \& Leadbeater, B. J. (1993). The problem of the other in research on theory of mind and social development. Human Development, 36(6), 350-362. doi:10.1159/000278223

Renk, K., \& Phares, V. (2004). Cross-informant ratings of social competence in children and adolescents. Clinical Psychology Review, 24(2), 239-254. doi:10.1016/j.cpr.2004.01.004

Ruffman, T., Perner, J., \& Parkin, L. (1999). How parenting style affects false belief understanding. Social Development, 8(3), 395-411. doi:10.1111/1467-9507.00103

Sabbagh, M. A., \& Taylor, M. (2000). Neural correlates of theoryof-mind reasoning: An event-related potential study. Psychological Science, 11(1), 46-50. doi:10.1111/14679280.00213
Sabbagh, M. A., Xu, F., Carlson, S. M., Moses, L. J., \& Lee, K. (2006). The development of executive functioning and theory of mind: A comparison of Chinese and US preschoolers. Psychological Science, 17(1), 74-81. doi:10.1111/j.14679280.2005.01667.x

Slaughter, V., Imuta, K., Peterson, C. C., \& Henry, J. D. (2015). Meta-analysis of theory of mind and peer popularity in the preschool and early school years. Child Development, 86(4), 1159-1174. doi:10.1111/cdev.12372

Smogorzewska, J., Szumski, G., \& Grygiel, P. (2019). The Children's Social Understanding Scale: An advanced analysis of a parent-report measure for assessing theory of mind in Polish children with and without disabilities. Developmental Psychology, 55(4), 835-845. doi:10.1037/ dev0000673

Tager-Flusberg, H. (1999). The challenge of studying language development in Children with autism. In L. Menn \& N. Bernstein Ratner (Eds.), Methods for studying language production (pp. 313-331). Mahwah, NJ: Lawrence Erlbaum.

Tahiroglu, D., Moses, L. J., Carlson, S. M., Mahy, C. E. V., Olofson, E. L., \& Sabbagh, M. A. (2014). The Children's Social Understanding Scale: Construction and validation of a parent-report measure for assessing individual differences in children's theories of mind. Developmental Psychology, 50(11), 2485-2497. doi:10.1037/a0037914

Vinden, P. G. (2001). Parenting attitudes and children's understanding of mind: A comparison of Korean American and Anglo-American families. Cognitive Development, 16(3), 793-809. doi:10.1016/S0885-2014(01)00059-4

Walker, S. (2005). Gender differences in the relationship between young children's peer-related social competence and individual differences in theory of mind. The Journal of Genetic Psychology, 166(3), 297-312. doi:10.3200/GNTP. 166.3.297-312

Wellman, H. M. (1992). The child's theory of mind. Cambridge, MA: MIT Press.

Wellman, H. M., \& Liu, D. (2004). Scaling of theory-of-mind tasks. Child Development, 75(2), 523-541. doi:10.1111/ j.1467-8624.2004.00691.x

Wellman, H. M., Cross, D., \& Watson, J. (2001). Meta-analysis of theory-of-mind development: The truth about false belief. Child Development, 72(3), 655-684. doi:10.1111/14678624.00304

Wimmer, H. \& Perner, J. (1983). Beliefs about beliefs: Representation and constraining function of wrong beliefs in young children's understanding of deception. Cognition, 13(1), 103-128. doi:10.1016/0010-0277(83)90004-5 


\section{In Korean}

Bae, K., \& Choi, B. (2002). The relationship between preschoolers' theory-of-Mind and relative variables. Korean Journal of Early Childhood Education, 22(2), 195-216.

Jang, M., \& Shin, N. (2018). Effects of maternal parenting behavior and preschoolers' executive function on preschoolers' theory of mind. Korean Journal of Child Study, 39(1), 103-117. doi:10.5723/kjcs.2018.39.1.103

Kim, Y., Hong, G., Kim, K., Jang, H., \& Lee, J. (2009). Receptive \& expressive vocabulary test (REVT). Seoul: Seoul Community Rehabilitation Center.

$\mathrm{Na}$, J. (2012). Maternal and paternal parenting behaviors affecting preschooler's social competence (Master's thesis). Retrieved from http://www.riss.kr/link?id=T12845592

Rhee, S. (2012). The study for the development and validation of Parenting Behavior Scale' parents with school-age children (Doctoral dissertation). Retrieved from http://www.riss.kr/
link?id=T12647827

Seo, J., \& Park, H. (2011). The effects of emotional intelligence on executive function: A comparison between normal children and attention deficit children. Journal of Cognitive Enhancement and Intervention, 2(1), 99-126.

\section{ORCID}

Sun-Young Yoon

Nana Shin http://orcid.org/0000-0002-4320-2388

http://orcid.org/0000-0002-7869-6875
Received February 29, 2020

Revision received March 25, 2020

Accepted March 26, 2020 